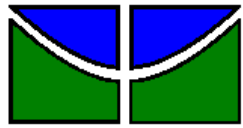 \\ Universidade de Brasília \\ Faculdade de Economia, Administração, Contabilidade \\ Departamento de Administração
}

Diana Corrêa da Silva Pires

Qualidade de Vida no Trabalho: Treinamentos e seus resultados na qualidade de vida no trabalho

Brasília - DF 


\section{Diana Corrêa da Silva Pires}

\section{Qualidade de Vida no Trabalho: Treinamentos e seus resultados na qualidade de vida no trabalho}

Projeto de monografia apresentado ao Departamento de Administração como requisito parcial à obtenção do título de Bacharel em Administração, na modalidade a distância, pela Universidade de Brasília (UnB).

Professor Orientador: Tatiane Paschoal

Professor Co-orientador: Jeferson Roberto Lima Pereira

Brasília - DF 
Pires, Diana Corrêa da Silva.

Qualidade de Vida no Trabalho: Treinamentos e seus resultados na qualidade de vida no trabalho / Diana Corrêa da Silva Pires - Brasília, 2011.

$28 \mathrm{fl}$ : : il

Monografia (Bacharelado) - Universidade de Brasília.

Departamento de Administração - EAD, 2011.

Orientador: Jeferson Roberto Lima Pereira Departamento de Administração

Qualidade de Vida 2. Treinamento 
Diana Corrêa da Silva Pires

\title{
Qualidade de Vida no Trabalho: Treinamentos e seus resultados na qualidade de vida no trabalho
}

A Comissão Examinadora, abaixo identificada, aprova o Trabalho de Conclusão do Curso de Administração da Universidade de Brasília do (a) aluno

(a)

\author{
Prof ${ }^{a}$. Dra Tatiane Paschoal \\ Professora Supervisora \\ Prof MSc Pedro Henrique Melo Albuquerque \\ Professor Avaliador \\ Prof. Espec. Jeferson Roberto Lima Pereira \\ Professor Orientador
}

Brasília, 03 de Dezembro de 2011 


\section{SUMÁRIO}

1. INTRODUÇÃO

2. REFERENCIAL TEÓRICO ................................................................. 10

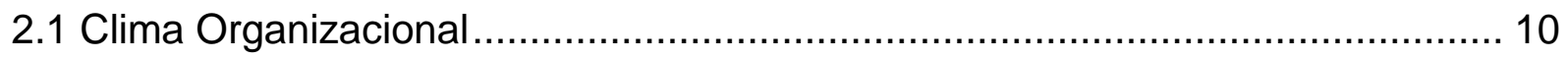

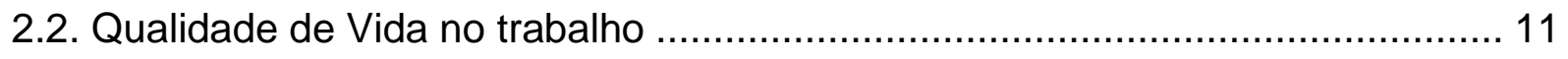

2.3 As práticas de treinamento no contexto organizacional.................................. 13

2.4 Os Impactos das práticas de treinamento.........................................................13

2.4.1 O estresse

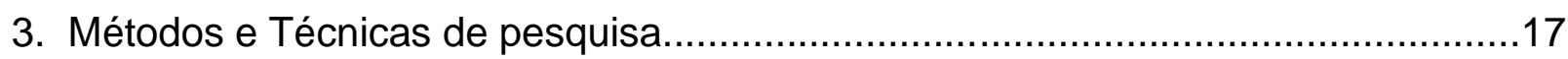

3.1 Caracterização da organização, setor ou área do objeto de estudo......................17

3.2 População e amostra ou participantes do estudo.............................................18

3.3 Caracterização dos instrumentos de pesquisa................................................18

3.4 Procedimentos de coleta e de análise de dados.............................................19

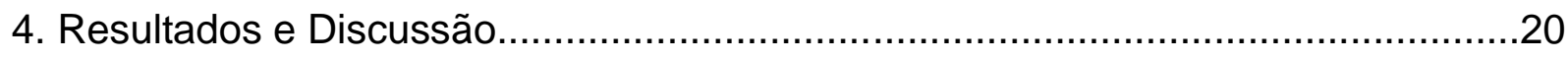

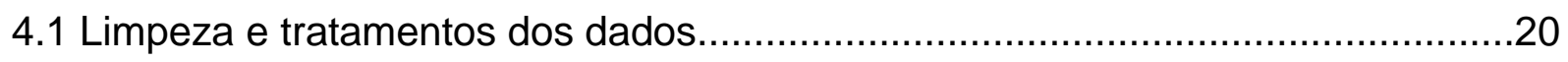

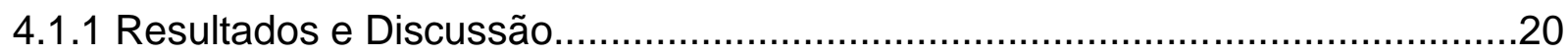

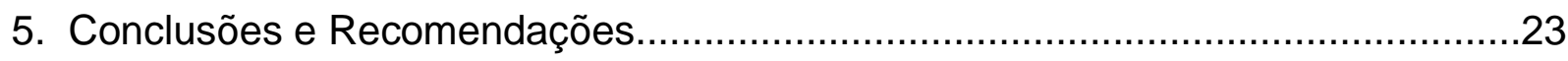

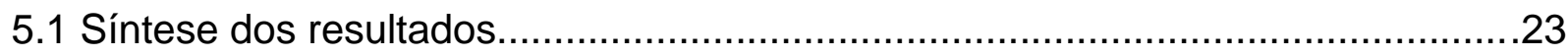

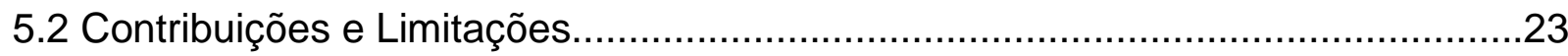

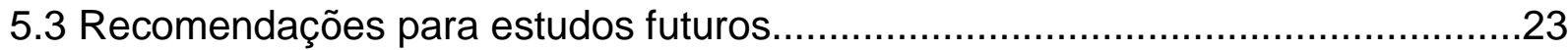

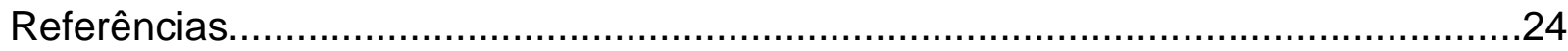

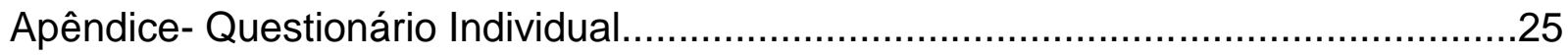


A área de Gestão de Pessoas, "é muito sensível à mentalidade que predomina nas organizações. Ela é contingencial e situacional, pois depende de vários aspectos como a cultura que existe em cada organização, a estrutura organizacional adotada, as características do contexto ambiental, o negócio da organização, a tecnologia utilizada, os processos internos e uma infinidade de outras variáveis importantes.

Gestão de Pessoas nada mais é do que o conjunto de práticas e políticas adotadas para conduzir do ponto de vista gerencial, os aspectos relacionados às pessoas mais comumente denominado nas organizações como: recursos humanos. A área de Gestão de Pessoas é voltada para o recrutamento, seleção, treinamento, recompensas e avaliação de desempenho.

É a área de Gestão de Pessoas, nos dias atuais a grande responsável pela excelência das grandes organizações, pois o aporte de capital intelectual simboliza o grande diferencial que é a importância do fator humano, mesmo na era da informatização.

Um dos grandes segmentos dentro da Gestão
de Pessoas é a Qualidade de Vida no
Trabalho, definida como sendo "o conjunto de
ações de uma empresa no sentido de
implantar melhorias e inovações gerenciais,
tecnológicas e estruturais no ambiente de
trabalho"- (Limongi-França, 1996).

CHIAVENATO, define que Qualidade de Vida no Trabalho "representa o grau em que os membros da organização são capazes de satisfazer as suas necessidades pessoais com sua atividade na organização". Quanto a grande questão que é sobre quais seriam os métodos necessários para alcançar a Qualidade de Vida no Trabalho, pois este é o grande objetivos das organizações de nosso tempo; torna-se o melhor lugar para se trabalhar, CHIAVENATO (2004b, pg.348) evidencia que, para isso é imprescindível que haja Qualidade de vida, definida por ele como "criar, manter e melhorar o ambiente de trabalho, sejam em suas condições físicas- Higiene e Segurança - sejam em suas condições psicológicas e sociais."

"A Qualidade de vida no trabalho, segundo Rodrigues (1991), é um modelo que surgiu na década de 50, na Inglaterra, a partir dos estudos de Eric Trist e colaboradores, do Tavistock Institute, pretendendo analisar a relação indivíduo-trabalho-organização. Esses pesquisadores desenvolveram uma abordagem sócio-técnica da organização do trabalho, 
tendo como base a satisfação do trabalhador no trabalho e em relação a ele.

No entanto, só a partir da década de 60 , houve um novo impulso nos movimentos de Qualidade de vida no trabalho, sendo desenvolvidas inúmeras pesquisas sobre melhores formas de realizar o trabalho, enfocando aspectos da saúde e bem-estar geral dos trabalhadores. A Qualidade de vida no trabalho tem sido pesquisada em diversos países. No Brasil, só a partir dos anos 80, foram realizados alguns estudos, ainda muito influenciados pelos modelos estrangeiros.

Dentre os pólos de desenvolvimento dessas pesquisas no país, destacam-se a Embrapa, em Brasília, e as Universidades Federais do Rio Grande do Sul e Minas Gerais. Apesar de inúmeros estudos sobre essa temática, o conceito de Qualidade de vida no trabalho está longe da unanimidade. Fernandes (1988) esclarece, no entanto, que os diversos conceitos de Qualidade de vida no trabalho voltam-se, geralmente, para três principais aspectos: a reestruturação do desenho dos cargos e novas formas de organizar o trabalho; a formação de equipes de trabalho semi-autônomas ou auto-gerenciadas; e a melhoria do meio ambiente organizacional".

As questões de vida familiar, atividades de saúde e lazer, expectativa de vida, convívio social, são apontadas como desencadeadoras de Qualidade de Vida no Trabalho e encontram-se bastantes presentes no tempo livre do trabalhador, não há como o trabalhador produzir bem se algo estive errado em seu Estilo de Vida. Neste contexto verifica-se que, a questão da Qualidade de Vida no Trabalho é bastante correlacionada com o Estilo de Vida pessoal do indivíduo, pois a condição humana no trabalho tornou uma das principais preocupações dos gestores da atualidade.

Já França (2004, pg 42) afirma que há uma "íntima correlação entre melhoria da Qualidade de Vida das pessoas e Estilo da vida dentro e fora da organização", e que essa melhoria "causará impacto na excelência e na produtividade dos indivíduos em seu trabalho".

Como visto no artigo, (Condições de vida do trabalhador docente: Associação entre estilo de vida e qualidade de vida no trabalho de professores de educação física), no referido artigo a correlação é mais destacada, pois na coleta de dados do artigo utilizaram questionários para avaliar a Qualidade de vida no Trabalho, quanto ao Estilo de Vida.

A falta das boas práticas de Qualidade de vida no trabalho atinge o trabalhador e deprecia sua qualidade de vida de modo em geral, mostrando a necessidade de aliar a Qualidade de Vida no Trabalho com o Estilo de Vida, para permitir as empresas públicas e privadas a 
obtenção de resultados mais eficientes e eficazes para seus colaboradores.

Os resultados mostram que as práticas de Qualidade de Vida no Trabalho, se caracterizam por nítido descompasso entre problemas existentes e atividades realizadas, com a abordagem de Qualidade de Vida no Trabalho de viés assistencialista, que tem no trabalhador a variável de ajuste. A análise dos dados fornece importantes elementos para uma agenda de trabalho, tanto acadêmica quanto organizacional, com uma abordagem de Qualidade de Vida no Trabalho de natureza preventiva, conforme ( M.C.Ferreira \& cols., 2009).

Em relação ao tema em questão destaca-se que o enfoque principal é buscar uma prevenção, para evitar que os profissionais entrem no círculo vicioso da era moderna: Sucumbir ao estresse e, através dele desenvolver um quadro depressivo, sendo que os prejuízos serão tanto do trabalhador quanto das organizações, pois "fica difícil estabelecer uma separação entre comportamento das pessoas e organizações. As organizações funcionam através das pessoas que delas fazem parte, que decidem e agem em seu nome", (CHIAVENATO, Gestão de Pessoas, $3^{\mathrm{a}}$ Edição - 2008).

\subsection{Formulação do problema}

A Qualidade de Vida no Trabalho prega o respeito por todos, a valorização da vida de cada individuo e a valorização dos bens coletivos e sendo treinamento "um investimento feito no intangível, mas que traz profundas conseqüências motivacionais, morais e de auto-estima às pessoas, pois na medida em que aumenta sua capacitação profissional e seu rendimento, aumenta também o seu desempenho, seu valor, sua consciência, suas expectativas e seus objetivos individuais.E tudo isso leva forçosamente ao sucesso organizacional."(Chiavenato, 2009).

Com base no texto de Chiavenato e fazendo uma síntese também com os artigos utilizados para a pesquisa: "Qualidade de Vida no Trabalho e Saúde"- Francisco Antônio de Castro Lacaz; "Gestão de Qualidade de Vida no Trabalho (QVT) no serviço público federal: o descompasso entre problemas e práticas gerenciais" -Mário César Ferreira; Luciana Alves; Natália Tostes; "Análise da Qualidade de Vida no trabalho de colaboradores com diferentes níveis de instrução através de uma análise de correlações"- Luciana da Silva Timossi; Antonio Carlos de Francisco; Guatacara dos Santos Junior; Antonio Augusto de 
Paula Xavier; "Condições de vida do trabalhador docente: Associação entre estilo de vida e qualidade de vida no trabalho de professores de Educação Física "-J.Both; J.V.Nascimento; C.N.Sonoo; C.A.F.Lemos; A.F.Borgatto; "Avaliação da gestão de programas de qualidade de vida no trabalho"- Patrícia Morilha de Oliveira; Ana Cristina Limongi-França, objetiva-se entender a questão: "Que resultados a Qualidade de Vida no Trabalho tendo o treinamento como uma de suas práticas, traz para as organizações?".

Onde hoje temos o treinamento visto apenas do ponto de vista motivacional, busca-se conhecer a sua real relação com a qualidade de vida no trabalho, bem como avaliar às práticas sistêmicas da mesma, na organização escolhida para a pesquisa, ao mesmo tempo em que tentar analisar os resultados conjuntamente com sua representatividade para a sociedade como um todo, pois estamos ligados com nosso lado funcional (trabalho, carreira e etc) e emocional (qualidade de vida, convívio, participação efetiva na sociedade).

Problema de Pesquisa: Que resultados a Qualidade de Vida no Trabalho tendo o treinamento como uma de suas práticas, traz para as organizações?

\subsection{Objetivo Geral}

Identificar a correlação dos resultados existentes entre as práticas de treinamentos e de qualidade de vida no trabalho.

\subsection{Objetivos Específicos}

1.3.1 Caracterizar o ambiente organizacional no qual os trabalhadores encontram-se inseridos

A análise e caracterização da organização são primordiais para se identificar se os treinamentos existentes atendem as necessidades da mesma.

Quais são os objetivos do treinamento, que meios se utilizam para o mesmo e a análise da interação da empresa, sobre as questões que envolvem as metas e o próprio modelo de gestão da empresa, devem ser caracterizados.

"As organizações são entendidas como conjuntos integrados e articulados de competências sempre atualizadas e prontas para serem aplicadas a qualquer oportunidade que surja, antes que os concorrentes o façam". (Chiavenato, 2010, p.10-11). 


\subsubsection{Apresentar as principais práticas de Treinamento}

Buscar-se-á apresentar as principais práticas de treinamento existentes na organização escolhida. Se forem presenciais, virtuais, quais os mecanismos e meios utilizados e etc.

Sendo o treinamento um processo pelo qual as pessoas aprendem conhecimentos e habilidades técnicas, suas práticas são necessárias e ajudam tanto as pessoas envolvidas no processo diretamente, quanto as demais de todos os níveis da organização. (Chiavenato, 2009).

\subsubsection{Descrever os impactos dos programas de treinamentos}

Na presente pesquisa buscar-se-á descrever os impactos dos programas de treinamentos no ambiente organizacional e funcional da empresa pesquisada, que melhorias eles trazem para a organização, que situações se desenham apartir das práticas dos mesmos.

Quais são essas melhorias especificamente que se dão por estas práticas.

Descrever se existem impactos tanto no ambiente organizacional, quanto no estilo de vida dos participantes.

Se haverá mudanças de comportamento em relação aos cargos, e possibilidades de mudança organizacional decorrente dos impactos dos treinamentos.

\subsection{Justificativa}

Sendo a área de Gestão de Pessoas na atualidade, a grande responsável pela excelência das grandes organizações, pois visa a manutenção, capacitação e valorização de seu aporte intelectual, a importância e identificação das práticas de Qualidade de Vida no Trabalho se mostram incontestável. Hoje todos têm acesso à tecnologia, inovação, logo o diferencial das organizações é seu capital intelectual. A Qualidade de Vida no Trabalho prega o respeito por todos, valorização da vida de cada individuo e a valorização dos bens coletivos.

Desde seu surgimento na década de 50 , até os dias de hoje, é um tema que merece ser estudado, sempre buscando "o conjunto de ações de uma empresa no sentido de implantar melhorias e inovações gerenciais, tecnológicas e estruturais no ambiente de trabalho"(Limongi-França, 1996).

A qualidade de vida é tão abrangente que seus resultados são sentidos tanto para os trabalhadores e organizações, quanto na sociedade como um todo. 
Os vários e inúmeros estudos sobre a temática da Qualidade de Vida no Trabalho, não chegaram ainda a uma unanimidade, sendo um tema que está longe de ser esgotado, e quanto mais se estudar e se buscar chegar a esta unanimidade; maiores e melhores serão as chances de sua mensuração e melhor aplicabilidade nas organizações com os ganhos de todos os direta ou indiretamente atingidos pelas práticas das mesmas.

Onde não existem as boas práticas da Qualidade de Vida no Trabalho, existe um trabalhador sem motivação, sem perspectiva pessoal ou profissional, conseqüentemente a beira da estagnação. Logo a organização onde o mesmo esteja inserido não poderá contar com sua capacidade de criação ou mesmo seu total desempenho, o que afetará seu aporte humano, o seu diferencial nos dias atuais.

Sendo a área de Gestão de Pessoas na atualidade, a grande responsável pela excelência das grandes organizações, pois visa à manutenção; capacitação e valorização de seu aporte intelectual, a importância das práticas de Qualidade de Vida no Trabalho se mostra incontestável.

Apesar de se dizer que treinamento é apenas motivacional, e não tido como práticas de qualidade de vida no trabalho, a presente pesquisa busca também responder essa questão, pois treinamento "Trata-se de um investimento feito no intangível, mas que traz retornos tangíveis à organização, ao cliente, à sociedade e, principalmente, aos colaboradores envolvidos nesse maravilhoso processo". (Chiavenato, treinamento e desenvolvimento de recursos humanos, 2010, prefácio). 


\section{REFERENCIAL TEÓRICO}

\subsection{Clima Organizacional}

"A organização é a coordenação de diferentes atividades de contribuintes individuais com a finalidade de efetuar transações planejadas com o meio ambiente".(Chiavenato, treinamento e desenvolvimento de recursos humanos, $7^{\underline{a}} \mathrm{Ed}$. Manole, 2010).

Cada ambiente organizacional é próprio e cheio de suas particularidades, sua cultura, o meio ao qual está inserido. Para a boa caracterização do ambiente organizacional da empresa pesquisada vamos levar em conta as seguintes competências:

- organizacionais- liderança e participação no mercado, vantagem competitiva, imagem/reputação, preferências-clientes/consumidores.

- funcionais- marketing, finanças, produção e administração de recursos humanos

- gerenciais- liderança e comunicação, motivação, espírito de equipe, relacionamento interpessoal, flexibilidade, contribuir e agregar valor, vontade de crescer e desenvolver.(Chiavenato, 2010).

Confiança organizacional, é uma das características do bom ambiente organizacional. Essa confiança organizacional é o resultado da relação entre o sistema formal das leis e regulamentos institucionais da organização e as medidas de sustentação de toda a organização. (Limongi-França, 2010).

Também como aspectos que devem ser levados em conta na caracterização do ambiente organizacional da empresa pesquisada são sua representatividade no segmento de atuação, a utilização de tecnologia nos processos de gestão e produção e a funcionalidade da sua estrutura organizacional em todos os níveis de sua hierarquia (Sant'Anna e Kilimnik, 2011).

A presente pesquisa irá identificar a realidade onde os trabalhadores da entidade encontram-se inseridos, levando em conta que na nova era busca-se está no seu tempo, atuante e a realidade de hoje prima pela competitividade, o aprimoramento pessoal como grande diferencial. 
A própria organização está em competição com as demais existentes no mercado, hoje a globalização leva a isso, superação é uma busca constante, superar-se e manter-se no mais alto patamar, atualizar-se sempre e trazer inovações pra seu segmento.

"As organizações são entendidas como
conjuntos integrados e articulados de
competências sempre atualizadas e prontas
para serem aplicadas a qualquer oportunidade
que surja, antes que os concorrentes o
façam". (Chiavenato, 2010, p.10-11).

Buscar a realidade na qual a empresa está inserida, suas aspirações, suas contribuições para a sociedade, como questões decisivas do nosso tempo que é a sustentabilidade, mostram-se imprescindíveis para essa pesquisa.

\subsection{Qualidade de Vida no Trabalho}

\subsubsection{Gestão de Pessoas}

"As pressões relativas ao contexto externo têm sido bastante estudadas, enquanto as relativas ao contexto interno não têm sido ainda objeto de grande aprofundamento". (Dutra, 2002).

Como pressões externas têm a conhecida globalização, as agitações do ambiente; bem como os serviços e produtos de grande valor agregado.

E no contexto interno têm as pressões com vistas a aspectos de maior liberdade, autonomia, possibilitando aos colaboradores um maior desenvolvimento de suas responsabilidades, contando com permanentes processos de desenvolvimento e aprendizagem profissional, podendo manter suas competências e aptidões com as quais a empresa precisa e busca para atingir suas metas e objetivos.

A importância da área de Gestão de Pessoas que tem o treinamento como uma de suas funcionalidades, é de sobremaneira vital.

Vários autores têm uma definição sobre o que seja Gestão de Pessoas, mas chama atenção a citada por Gil (2001):

Gestão de Pessoas é um ramo especializado da Ciência da Administração que contempla 
todas as ações empreendidas por uma organização, com o objetivo de integrar 0 colaborador no contexto da organização e aumentar sua produtividade.

Integração é aumento de produtividade, assim enquanto gerir pessoas é se preocupar com o individuo, onde o colaborador terá ganhos com o foco em sua direção, conseqüentemente a empresa terá ganhos, pois a produtividade de seu colaborador será revestida na organização tanto a médio quanto a longo prazo.Pois a integração não é apenas o ingresso do colaborado na empresa, ela é toda sua vivência de atuação na mesma.

$\mathrm{Na}$ atualidade existe um conceito que as empresas adotam para gerir seus colaboradores e garantir sua posição de sucesso, entre seus vários concorrentes: Ter a Gestão de pessoas como a capacidade de mover seus colaboradores em busca do alcance dos objetivos da organização, através de estratégias com vistas a comprometê-los, entusiasmá-los e motiválos, pois não existe ambiente organizacional sem pessoas e são as pessoas que fazem parte do ambiente organizacional, fazem parte da empresa. Criar parceria, evitar o confronto, este é o objetivo do ambiente organizacional.

Se os colaboradores têm suas expectativas: que são sua realização pessoal, crescimento, melhorias salariais acrescidas de benefícios, segurança no trabalho, respeito e conhecimento, Qualidade de vida e várias mais; as quais desejam atingir, através de seu empenho na função por ele exercida. As empresas também possuem as suas como alcançar novos mercados, maior produção e lucro, sustentar seu crescimento e poder oferecer acrescer uma maior qualidade em seus produtos e serviços, eles na realidade são parceiros onde a realização de um torna-se a realização do outro.

É dentro desses contextos que a área de Gestão de Pessoas está inserida, buscando a reunião de parcerias e empenhos, utilizando-se da manutenção das relações, com sinergia para que assim todos possam ter um mesmo norte.

Gestão de pessoas é composta pela reunião de estratégias, com procedimentos e técnicas, e foco no incentivo de talentos, dons naturais, potencialidades, conhecimentos e capacidades existentes nos seus colaboradores. 


\subsection{As práticas de treinamento no contexto organizacional}

Existem hoje treinamentos com a utilização de filmes, televisão, slides, estudos de caso, discussão em grupo, dramatização, simulação, a criatividade nesta área é enorme e está em constante renovação. (Chiavenato, 2010).

O processo de treinamento assemelha-se a
um modelo de sistema aberto, cujos
componentes são: Entradas, Processamento
ou operação, saídas, retroação".(Chiavenato,
2010, p.49).

Treinamento é ato intencional para gerar aprendizagem (Chiavenato, 2010). A organização tem em seus empregados sua continuidade ou não, logo devem se preocupar em influenciá-los, através de treinamentos constantes para que os mesmos estejam aptos para desenvolver a contento suas funções chegando ao resultado esperado pela empresa e conseqüentemente alcançando os objetivos da empresa e às vezes até mesmo suplantando suas expectativas.
As empresas precisam de pessoas motivadas para que o tão propalado binômio produtividade-qualidade aconteça. (Vergara, 2000, p.43).

Vemos que treinamento é aliado de motivação, motiva-se o profissional para que o mesmo possa cada vez mais se qualifica e através da geração de aprendizagem que o treinamento proporciona aumentar cada vez mais a qualidade do capital intelectual e funcional das organizações.

As modalidades de treinamento vigentes são bastante diversificadas, hoje as empresa têm acesso a treinamento desde forma presencial até a forma virtual e iremos identificar as utilizadas pela empresa da presente pesquisa. 


\subsection{Os impactos das práticas de treinamento}

Que melhorias os treinamentos trazem para as pessoas e para a organização, e também se não existem fatores negativos, como a questão do profissional se sentir inapto, não responder ao treinamento.Isso serve também para que a empresa repense a colocação do funcionário, fazendo remanejamento de cargos, de forma a tentar aliar a funcionalidade da empresa com a qualidade de vida do colaborador,

As organizações funcionam através das pessoas que delas fazem parte, que decidem e agem em seu nome, (Chiavenato, gestão de pessoas, 2008).

Logo os impactos causados nas pessoas, será refletido na organização, que espera-se ganhe retorno de capital investido nos treinamentos e práticas de qualidade de vida no trabalho, aumentando sempre a qualidade de seu capital intelectual.
“Um processo de mudança cognitiva, comportamental, profissional e atitudinal, mas que traz profundas conseqüências motivacionais, morais e de auto-estima às pessoas, pois na medida em que aumenta sua capacitação profissional e seu rendimento, aumenta também 0 seu desempenho, seu valor, sua consciência, suas expectativas e seus objetivos individuais. E tudo isso leva forçosamente ao sucesso organizacional".'(Chiavenato, 2010).

Para se adquirir aprendizagem, o treinamento é necessário e da aprendizagem nasce o conhecimento. Como fator negativo que se possa encontrar nos treinamentos, o seguinte texto pode ser um referencial:

Não se encontrará tipo algum de exercício tão saudável e inócuo que, praticado em excesso, não acarrete graves danos; disso se dão conta os mestres de dicção, autores, oradores, pregadores, frades, também as monjas pelo seu contínuo entoar de cânticos nos templos, os rábulas forenses os pregoeiros, os filósofos que lêem nas escolas discutindo até ficarem roucos, e todos aqueles que têm por ofício cantar e forçar a voz.Geralmente estão herniados, com exceção dos eunucos, por ablação dos testículos."(Limongi-França, 2010, p.185).

Para evitar a criação desses problemas, deve existir uma dosagem certa para que 0 treinamento, que deve ser uma prática de qualidade de vida no trabalho não passe a ser um agravante dos problemas já existentes pela falta de práticas sistêmicas e preventivas da 
qualidade de vida no trabalho.

\subsubsection{O estresse}

O "estresse é um conjunto de reações físicas, químicas e mentais de uma pessoa a estímulos ou estressores no ambiente. É uma condição dinâmica, na qual uma pessoa é confrontada com uma oportunidade, restrição ou demanda, relacionada com o que ela deseja”.(CHIAVENATO, 1999).

Vários fatores são acarretadores de estresse: o autoritarismo da chefia, desconfiança, pressões, exigências e cobranças, o cumprimento do horário de trabalho, a chateação e monotomia de certas tarefas, o moral baixo de certos colegas, falta de percepção de futuro profissional e insatisfação pessoal, não somente derrubam o bom humor das pessoas, como também provocam estresse no trabalho. (CHIAVENATO, 1999).

Fora o trabalho, as dificuldades do cotidiano como crises: conjugal e financeira, só reforçam o estresse dos colaboradores.

As conseqüências do estresse são danosas tanto para o colaborador quanto para a organização onde ele está inserido.

Como prevenção deve ser sempre a melhor opção, a organização que foca funcionalidade e eficiência, tem a saúde ocupacional; que está relacionada com assistência médica preventiva, como uma de suas prerrogativas, utilizando-se de programas de medicina ocupacional presentes e ativos na sua empresa.

Quatro são as etapas de um programa de saúde ocupacional:

- Estabelecimento de um sistema de indicadores, abrangendo estatísticas de afastamentos e acompanhamentos de doenças;

- Desenvolvimento de sistemas, de relatórios médicos;

- Desenvolvimento de regras e procedimentos para prevenção médica;

- Recompensas aos gerentes e supervisores pela administração eficaz da função de saúde ocupacional.

Segurança no trabalho cuida da prevenção de doenças e também dos acidentes que se relacionam com o trabalho. Preocupa-se com as condições ambientais que tanto 
asseguram a saúde física quanto a mental aos colaboradores.

Com base nas normas BSI 8800 e OBHAS 18001, um crescente número de organizações nacionais e multinacionais, têm nos últimos anos investindo para o desenvolvimento de sistemas integrados de gestão, segurança, saúde e meio ambiente, demonstrando com isso seu comprometimento com as responsabilidades sócio-ambientais, ampliando e fortalecendo sua postura e posição em um mercado tão globalizado na nossa atualidade. 


\section{MÉTODOS E TÉCNICAS DE PESQUISA}

O método é um procedimento, ou seja, um conjunto de processos que são necessários para o alcance final de uma investigação. Dessa forma, método também pode ser entendido como o procedimento geral, ou o caminho que é percorrido em uma investigação (ZANELLA, 2006). Para Bunge (1980 apud ZANELLA, 2006, p. 20) o "método é um procedimento regular, explícito e passível de ser repetido para conseguir-se alguma coisa, seja material ou conceitual".

Cervo e Bervian (2002 apud ZANELLA, 2006) reforçam que o método se materializa a partir de um conjunto de diversas etapas que devem ser dados para a realização da pesquisa. $A$ metodologia de pesquisa tem como objetivo "identificar e analisar os recursos metodológicos, assinalar suas limitações, explicitar seus pressupostos e as conseqüências de seu emprego" (ASTI VERA, 1974 apud ZANELLA, 2006, p. 20).

\subsection{Caracterização da organização, setor ou área do objeto de estudo}

A Universidade do Pará foi criada pela lei $n^{\circ}$ 3.191, de dois de Julho de 1957, sancionada pelo Presidente Juscelino Kubitschek de Oliveira, após cinco anos de tramitação legislativa. Este trabalho foi realizado no Campus de Altamira-PA, que iniciou suas atividades em 1987, apenas com cursos intervalares de Letras, Pedagogia, Matemática, História e Geografia, a partir de 1992, foram instalados os cursos regulares.

O Campus de Altamira-PA, que está localizado na Rua José Porfírio, no 2515, no Bairro de São Sebastião, e está dividida em dois campi, no primeiro fica o Centro Administrativo, um auditório, o colegiado dos cursos de Letras, Pedagogia e Biologia, além de um laboratório de informática, os sete blocos de salas e de alojamento. Na área do Campus I, há ainda um prédio onde funciona a sede da FUNAI. 
No Campus II, a Biblioteca, o laboratório de Análise de Solo, o colegiado de Ciências Agrárias e os cinco blocos de sala de aula completam a estrutura da Universidade. Atualmente o Campus de Altamira conta com os cursos de graduação em Ciências Biológicas (Regular), Agronomia (Regular), Letras (Regular e Intervalar), Pedagogia (Regular e Intervalar), e Engenharia Florestal.

\subsection{População e amostra ou participantes do estudo}

A pesquisa foi realizada com docentes e técnicos da UFPA, Campus de Altamira-PA.

\begin{tabular}{|l|l|l|}
\hline Faculdades & & \\
\hline Educação & 16 & \\
\hline Letras & 9 & \\
\hline Letras- Inglês & 8 & \\
\hline Agronomia & 13 & \\
\hline Biológia & 20 & \\
\hline Florestal & 15 & \\
\hline Geografia & 11 & \\
\hline Étino Desenvolvimento & 03 & \\
\hline Técnicos & & \\
\hline Técnicos & 19 & \\
\hline Total & 104 & \\
\hline
\end{tabular}

\subsection{Caracterização dos instrumentos de pesquisa}

A pesquisa utilizou um questionário com cinco perguntas, sendo a quinta pergunta, uma pergunta aberta. As perguntas foram voltadas para a satisfação das práticas de Qualidade de Vida no Trabalho implantadas pela empresa (entidade), se existia treinamentos na mesma e se os participantes consideravam que os treinamentos afetavam de forma positiva sua Qualidade de Vida no Trabalho. Como existia a opção de sim e não e ainda um pedido 
de justificativa, as respostas foram bastante uníssonas. O mais observado é que por estarem inseridos no interior, sentem uma disparidade em relação aos inseridos na capital.

\subsection{Procedimentos de coleta e de análise de dados}

O questionário foi entregue na empresa (entidade) após autorização do vice-coordenador Profo Francisco Plácido Magalhães Oliveira, por escrito e através da ajuda da administração quarenta questionários ficaram na secretária por um período de duas semanas.

A análise dos dados foi realizada por meio de estatística descritiva que utiliza de gráficos e tabelas para mensurar e interpretar os dados coletados. 


\section{RESULTADOS E DISCUSSÃO}

\subsection{Limpeza e tratamento dos dados}

Foram distribuídos 40 questionários, sendo 09, dessa forma, os quais foram utilizados na íntegra. Considera-se que a quantidade de questionários recebida foi satisfatória, pois representa $22,5 \%$ do universo pesquisado. O primeiro objetivo proposto foi diagnosticar o clima organizacional. Através das perguntas dos questionários, têm-se o embasamento sobre o clima organizacional da empresa (entidade) pesquisada.

\subsection{1- Resultados e discussão}

4.1.2 - Você está satisfeito com as práticas de Qualidade de Vida no Trabalho implantadas pela sua empresa?

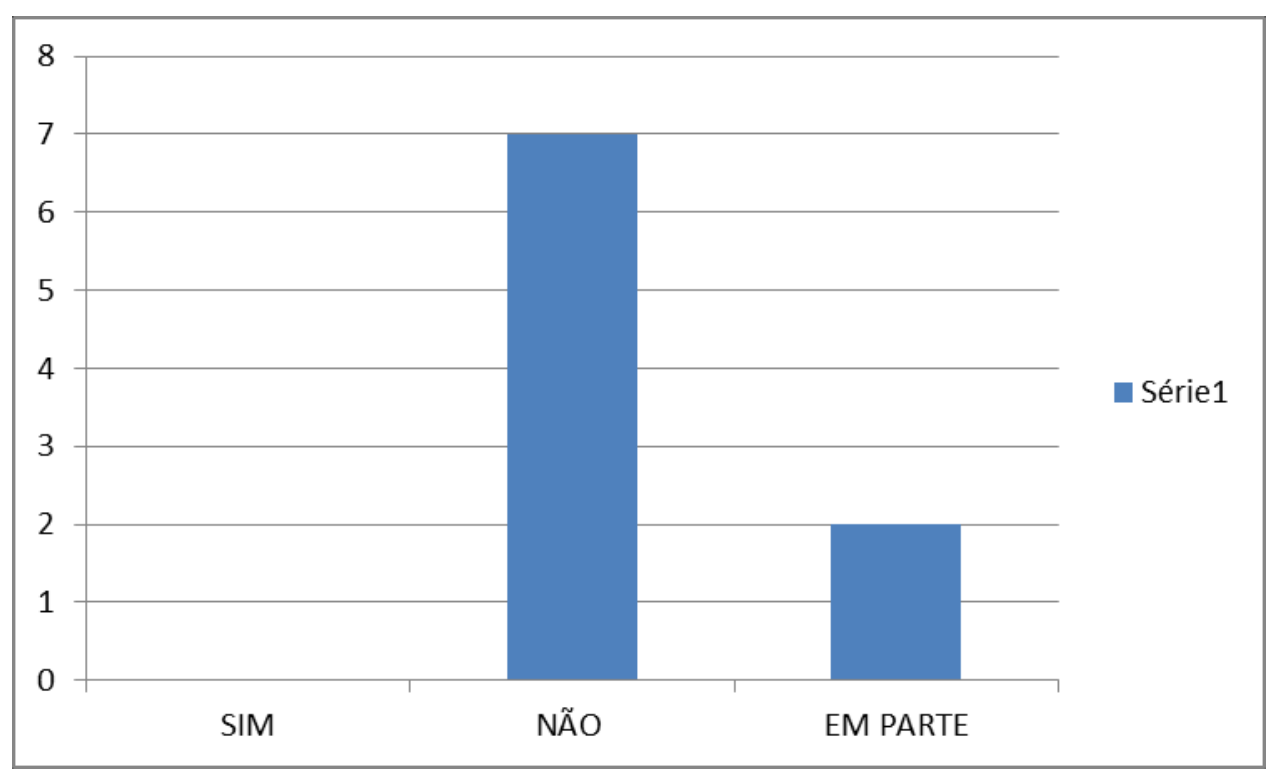

Dos nove questionários respondidos, sete resultaram em não para a questão da satisfação das práticas de Qualidade de Vida no Trabalho da sua empresa e dois marcaram que em parte estavam satisfeitos.

O que chamou a atenção foi que dos sete que disseram não está satisfeitos, três justificaram sua resposta dizendo não existir tão prática no campus do interior, e dois se mostraram insatisfeitos por não observarem tal prática na empresa (entidade), tendo um dos mesmos relatados que observa a falta da mesma principalmente na assistência à saúde. 


\subsubsection{Os programas de treinamentos da empresa são satisfatórios?}

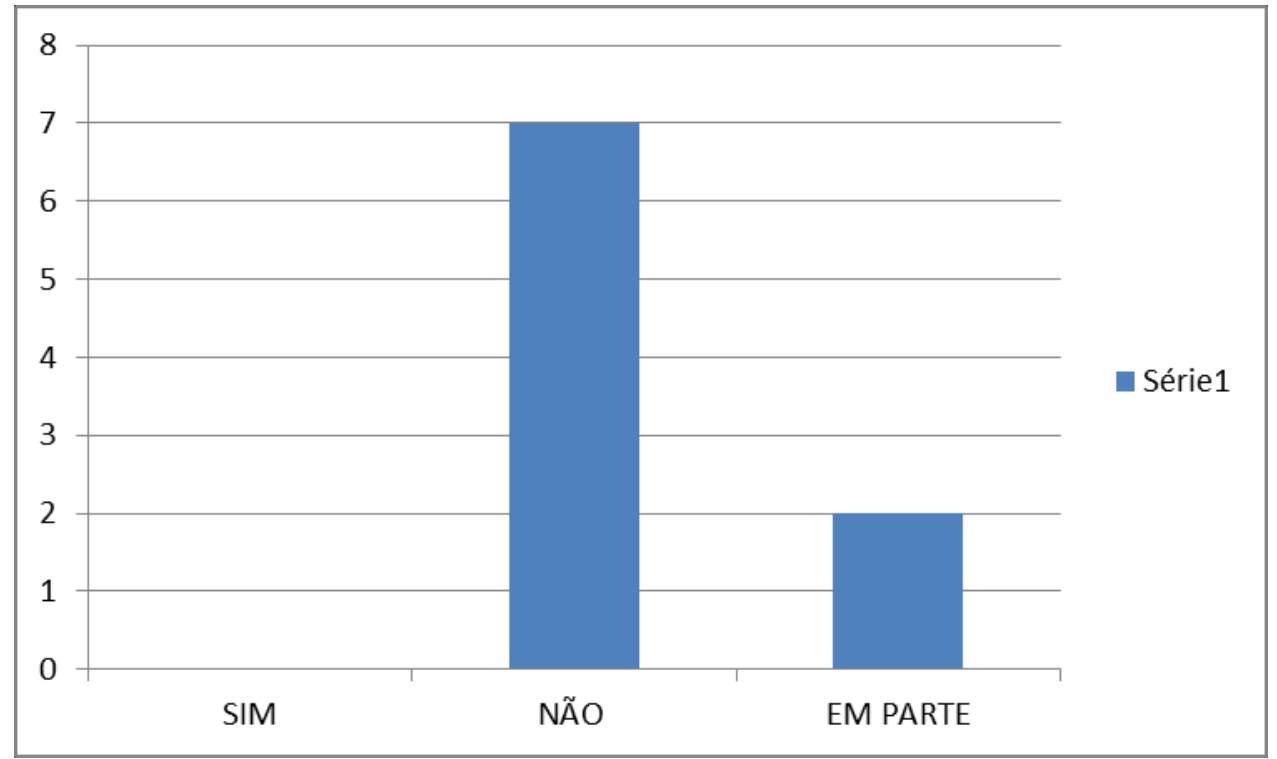

Dos nove questionários respondidos, apenas dois acharam satisfatórios os treinamentos e sete disseram não achar satisfatórios os treinamentos existentes. Levando-se em conta que sete já haviam se manifestados como insatisfeitos pelas práticas de Qualidade de Vida no Trabalho, quando questionados sobre os treinamentos demonstraram a mesma insatisfação

\subsubsection{Quais os tipos de treinamentos que existem na sua empresa?}

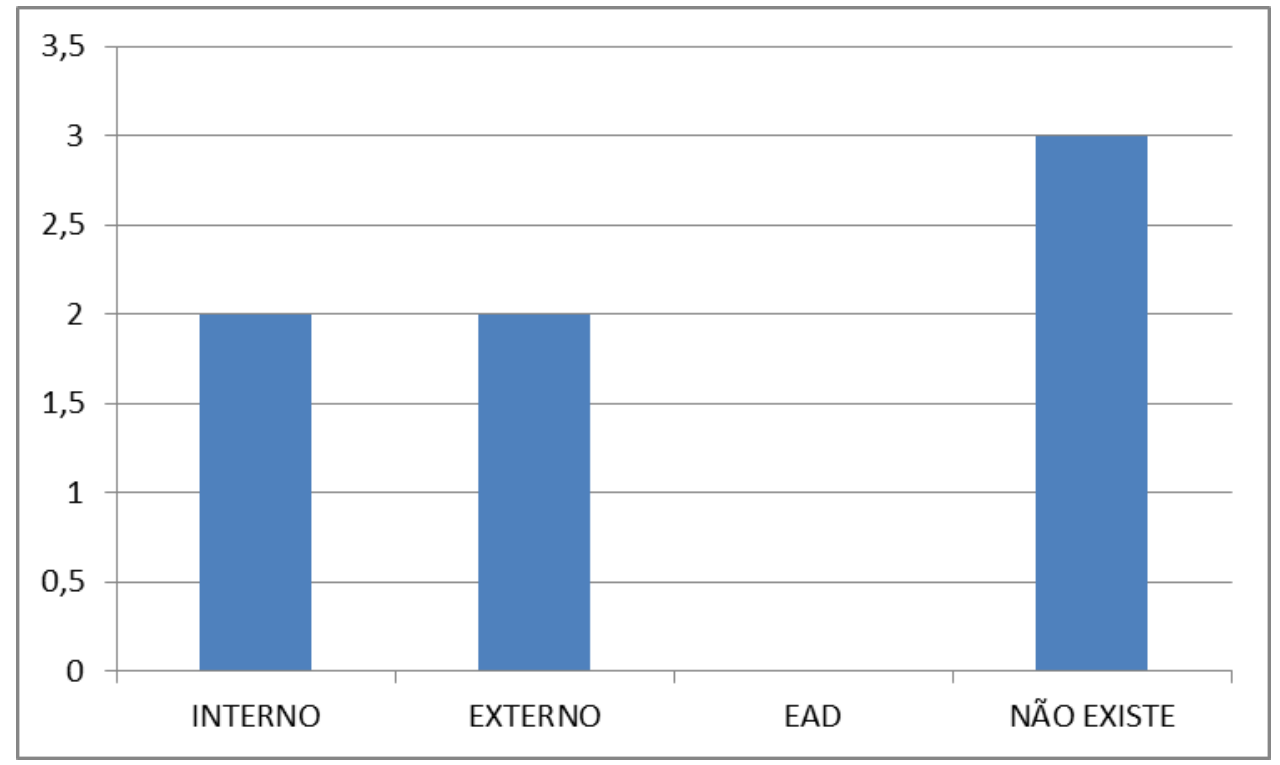


Quando questionados sobre os tipos de treinamentos, dois marcaram internos, dois externos e três que não existem treinamentos. Ainda dois não marcaram por não se acharem aptos à responder à pergunta.

4.1.5 Você considera que os programas de treinamentos melhoram a Qualidade de Vida no Trabalho?

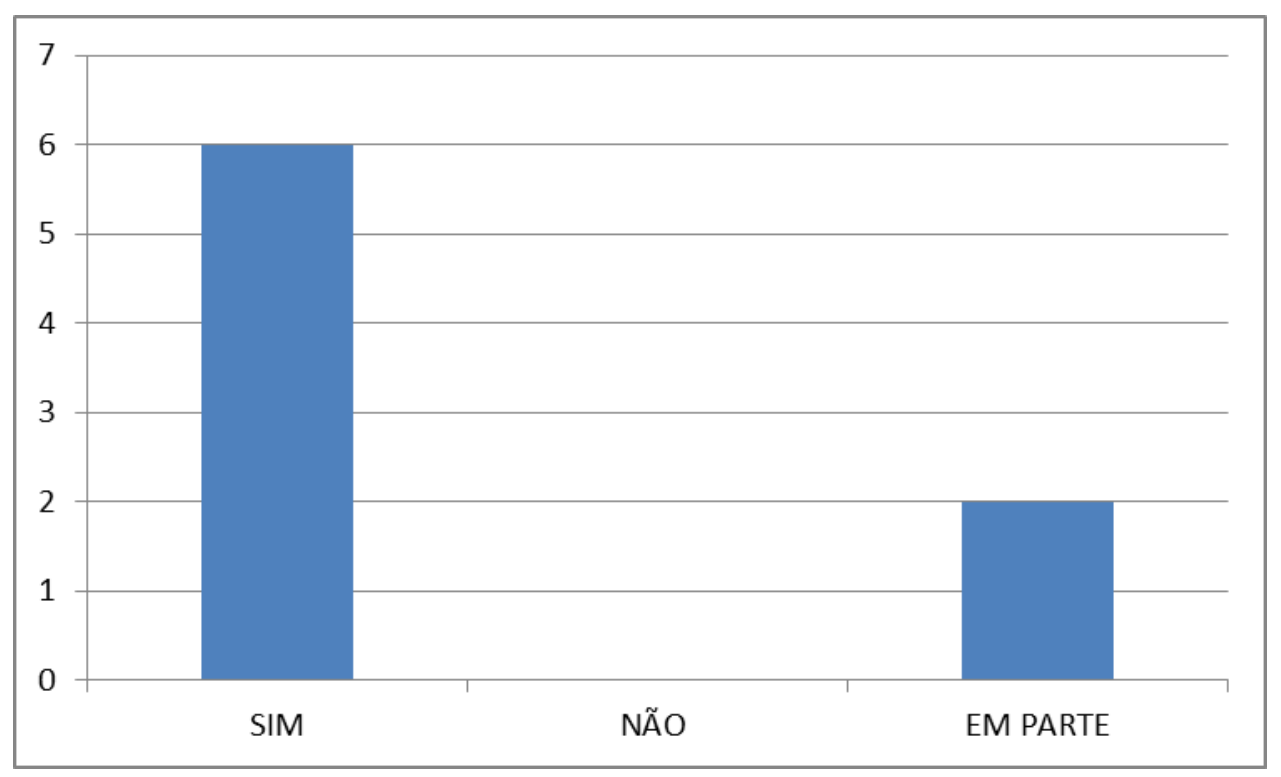

Seis responderam que sim, que os programas de treinamentos melhoram a Qualidade de Vida no Trabalho, dois responderam que em parte e um disse nenhuma das anteriores e não justificou.

Chama a atenção o fato de que a maioria vê nos programas de treinamentos uma melhoria da Qualidade de Vida no Trabalho.

\subsubsection{Pergunta aberta- Formule a pergunta a qual deseja responder.}

Apenas dois dos que responderam a pesquisa formularam uma pergunta: $O$ auxílio à assistência à saúde é aplicado em seu local de trabalho? Quais treinamentos você gostaria que existissem na sua empresa? 


\section{CONCLUSÕES E RECOMENDAÇÕES}

\subsection{Síntese dos resultados}

Segundo Ulrich (1998), a Gestão de Pessoas, através de seus profissionais, precisa desenvolverem e aplicar três capacidades: Criar Clareza Estratégica; fazer com que as mudanças aconteçam; criar Capital Intelectual. Essas três capacidades representam os resultados a serem alcançados a médio e longo prazo.

E não há como pensar em Gestão de Pessoas, sem considerar Qualidade de Vida no Trabalho. Nos dias de hoje onde vivenciamos uma acirrada competição global, treinamento é um grande aliado da Qualidade de Vida no Trabalho. Treinar por treinar não leva à nada, mas treinar por objetivos e se os resultados desse treinamento se relacionarem com os objetivos desejados a empresa ou entidade que bem souber terá aí um diferencial.

Treinamento não é apenas motivacional, é forma de incrementar talentos, torna o colaborador parte integrante do processo, ele sente-se prestigiado, visto como pessoa que merece sempre capacitar-se mais como forma de desenvolvimento pessoal também. $E$ tudo que envolve desenvolvimento pessoal, envolve qualidade de vida.

\subsection{Contribuições e Limitações}

Dentro dos resultados apresentados, onde a maioria vê sim ligação entre treinamentos e Qualidade de Vida no Trabalho, isso num universo de docentes e técnicos, pessoas com alto grau de conhecimento, sinto que minha pesquisa de certa forma demonstra uma resposta positiva ao questionamento de haver ou não relação entre treinamento e Qualidade de Vida no Trabalho. Como obtive pouco retorno de questionários, minhas limitações foram enormes e isto de certa forma foi grande empecilho para um melhor desenvolvimento da pesquisa.

\subsection{Recomendações para estudos futuros}

Claro que este tema é um tema muito abrangente e que está em constante estudo, pois parece ser algo que todos têm como necessário, mas que na prática apenas as grandes empresas já conceituadas globalmente falam e praticam realmente técnicas de Qualidade de Vida no Trabalho. Seu continuo estudo deve continuar, para que as práticas de Qualidade de vida no trabalho se tornem cada vez mais regra e deixem de ser exceção. 


\section{Referências}

CHIAVENATO, Idalberto, Treinamentos e Desenvolvimento de Recursos Humanos, $7^{\text {a }}$ Ed revisada, Ed. Manole, São Paulo, 2009.

LIMONGI-FRANÇA, Ana Cristina, Qualidade de vida no trabalho-QVT, conceitos e práticas nas empresas da sociedade pós-industrial, 2ª Ed, Ed. Atlas, São Paulo, 2010.

SANT'ANNA, Anderson de souza, KILIMNIK, Zélia Miranda, Qualidade de vida no trabalho, abordagens e fundamentos, Ed.Elsevier, 2011.

PUGLISI, Franco, 2005, pg.13

LACAZ, Francisco Antônio de Castro, Ciência \& Saúde Coletiva, vol 5; site www.scielo.br. FERREIRA,Mario César; ALVES, Luciana; TOSTES, Natalia, Teoria e Pesquisa, vol.25 ㄲo3; site www.scielo.br.

MORILHA DE OLIVEIRA, Patrícia; LIMONGI-FRANÇA, Ana Cristina; rae eletrônica, vol. 4 nº 11 , site www.scielo.br

TIMOSSI, Luciana; GUATAÇARA DO SANTOS, Junior; PAULA XAVIER, Antonio Augusto, Revista produção vol.20 no3, site www.scielo.br BOTH, J; NASCIMENTO; SONNO, CN; LEMOS, C.A.F; BORGATTO, A.F, Revista Motri vol. 6 no3, site www.scielo.br

DUTRA, Ademar, Gestão estratégica de pessoas, 3ª Edição revista e atualizada, 2007. 


\section{APÊNDICE}

Questionário Individual

Pesquisa sobre Qualidade de Vida no Trabalho:

1) Você está satisfeito com as práticas de Qualidade de Vida no Trabalho implantadas pela sua empresa?

( ) Sim ( ) Não ( ) Em parte

2) Os programas de treinamentos da empresa são satisfatórios?

( ) Sim ( ) Não ( ) Em parte

Justifique sua resposta:

3) Quais os tipos de treinamentos que existem na sua empresa?

( ) Internos ( ) Externos ( ) EAD ( ) Não existem treinamentos

4) Você considera que os programas de treinamentos melhoram a Qualidade de Vida no Trabalho?

( ) Sim ( ) Não ( ) Em parte

Justifique sua resposta:

5) Pergunta Aberta- Formule a pergunta a qual deseja responder. 